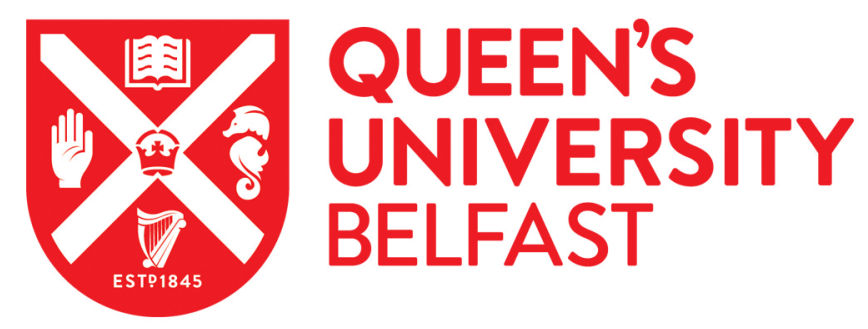

\title{
Mitigating of Arsenic Accumulation in Rice (Oryza sativa L.) from Typical Arsenic Contaminated Paddy Soil of Southern China Using Nanostructured a-MnO2: Pot Experiment and Field Application
}

Li, B., Zhou, S., Long, J., Peng, L., Tie, B., Williams, P., \& Lei , M. (2019). Mitigating of Arsenic Accumulation in Rice (Oryza sativa L.) from Typical Arsenic Contaminated Paddy Soil of Southern China Using Nanostructured a-MnO2: Pot Experiment and Field Application. Science of the Total Environment, 650(1), 546-556. https://doi.org/10.1016/j.scitotenv.2018.08.436

\section{Published in:}

Science of the Total Environment

Document Version:

Peer reviewed version

Queen's University Belfast - Research Portal:

Link to publication record in Queen's University Belfast Research Portal

\section{Publisher rights}

Copyright 2018 Elsevier.

This manuscript is distributed under a Creative Commons Attribution-NonCommercial-NoDerivs License

(https://creativecommons.org/licenses/by-nc-nd/4.0/), which permits distribution and reproduction for non-commercial purposes, provided the author and source are cited.

\section{General rights}

Copyright for the publications made accessible via the Queen's University Belfast Research Portal is retained by the author(s) and / or other copyright owners and it is a condition of accessing these publications that users recognise and abide by the legal requirements associated with these rights.

\section{Take down policy}

The Research Portal is Queen's institutional repository that provides access to Queen's research output. Every effort has been made to ensure that content in the Research Portal does not infringe any person's rights, or applicable UK laws. If you discover content in the

Research Portal that you believe breaches copyright or violates any law, please contact openaccess@qub.ac.uk. 


\section{Mitigating of Arsenic Accumulation in Rice (Oryza sativa L.)}

from Typical Arsenic Contaminated Paddy Soil of Southern

\section{China Using Nanostructured $\alpha-\mathrm{MnO}_{2}$ : Pot Experiment and}

Field Application

\section{Bingyu $\mathrm{Li}^{\text {abc }}$, Shuang Zhou ${ }^{\text {abcd }}$, Dongning Wei ${ }^{\text {abc }}$, Jiumei Long ${ }^{\text {abc }}$, Liang Peng ${ }^{\text {abc }}$,} Baiqing Tie $^{\text {abc }}$, Paul N. Williams ${ }^{\mathrm{e}}$, Ming Lei ${ }^{\mathbf{a b c}_{*}}$

${ }^{a}$ College of Resource \& Environment, Hunan Agricultural University, Changsha 410128, P. R. China

${ }^{b}$ Hunan Engineering Research Center for Safe and High-Efficient Utilization of Heavy Metal Pollution Farmland, Changsha 410128, P. R. China

${ }^{c}$ Provincial Key Laboratory of Rural Ecosystem Health in Dongting lake area, Hunan province, Changsha 410128, P. R. China

${ }^{d}$ Laboratory of Environmental Geology, Graduate school of Engineering, Hokkaido University, Kita 13 Nishi 8, Kita-Ku, Sapporo 060-8628, Japan

e Queen's University Belfast, Institute for Global Food Security, School of Biological Sciences, Belfast, BT9 5BN, United Kingdom

Corresponding Author at: College of Resource and Environment, Hunan Agricultural University, Changsha, 410128, PR China, Tel: +86073184617803

E-mail: leiming@hunau.edu.cn (M.Lei)*

\section{Abstract}

Manganese oxides are naturally occurring powerful oxidants and scavenger which can control the mobility and bioavailability of arsenic (As). However, the effect of synthetic nanostructured manganese oxides on the mobilization and transportation of As at actual paddy soils are poorly understood, especially in the low or medium background $\mathrm{Mn}$ concentration soil. In the present study, a novel Nano manganese 
oxide with higher reactivity and surface area has been synthesized. A 90-d soil incubation experiment combined with pot and field rice cultivation trials were designed to evaluate the effectiveness of exogenous $\alpha-\mathrm{MnO}_{2}$ nanorods on the mobilization and transportation of As in soil-rice systems. Our results proved that the addition of $\alpha-\mathrm{MnO}_{2}$ nanorods can effectively control the soil-to-solution partitioning of As under anaerobic conditions. After treatment with different amounts of $\alpha-\mathrm{MnO}_{2}$ nanorods, the content of effective As decreased with the increasing of residual As and insoluble binding As (Ca-As and Fe-As). Besides, the enhanced oxidation of As (III) into $\mathrm{As}(\mathrm{V})$ by $\alpha-\mathrm{MnO}_{2}$ nanorods increased the adsorption of As onto indigenous iron(hydr) oxides which greatly reduced the soil porewater As content. Additionally, pot experiment and filed applications are further proved that the influx of As into aerial parts of rice plants (stems, husk and leaves) was strictly prohibited after treatments with different amount of $\alpha-\mathrm{MnO}_{2}$ nanorods; more interestingly, significantly negative correlations have been observed between As and $\mathrm{Mn}$ in rice, which indicated that as $\mathrm{Mn}$ is increased in soil, As in brown rice decreases. Our results demonstrated that the use of $\alpha-\mathrm{MnO}_{2}$ nanorods in As polluted paddy soil containing low levels of background $\mathrm{Mn}$ oxides can be a promising remediation strategy.

\section{Keywords: Arsenic, Nanostructured-MnO $\mathrm{M}_{2}$, Rice, Accumulation, Paddy soil}

\section{Introduction}


ores (tungsten, bismuth, realgar) (Lei et al., 2015; Okkenhaug et al., 2012; Williams et al., 2009). In the past several decades, intensive mineral exploitation, ore extraction and refining activities have caused a large amount of toxic trace elements $(\mathrm{Cd}, \mathrm{Hg}, \mathrm{Pb}$ and As) to be discharged into farmland which has greatly affected the local soil and water environment(Li et al., 2017; Zhao et al., 2015). Among them, arsenic is a ubiquitous and highly toxic metalloid element that has caused severe contamination in Hunan province(Lei et al., 2013; Lei et al., 2015). It is reported that the arsenic-contaminated farmland in Hunan province has already seriously impaired the development of agriculture and posed a serious threat to the health of local residents, because rice is a dominant staple food (Li et al., 2016; Liao et al., 2005).

The existence forms (speciation) of arsenic may be more important than the total arsenic in the soil, which determine its effectiveness and toxicity to organisms. It is generally established that trivalent As species are more toxic than their pentavalent counterparts because they binds to sulfhydryl groups(-SH), impairing the function of many proteins (Fu et al., 2016; Liao et al., 2005; Liu, 2005). In paddy soils, arsenic is predominantly present as the inorganic species arsenate and arsenite (Takahashi et al., 2004). The extent of As mobility and bioavailability in paddy soil is, in part, regulated by the type of minerals exist in the soil system and the oxidation state of As (Fendorf and Kocar, 2009; Ying et al., 2012). Generally, As(III) are far more mobile than $\mathrm{As}(\mathrm{V})$; and the relative content of arsenate and arsenite in paddy soil are primarily depending on the redox status of soil (Yamaguchi et al., 2011). Arsenate often exists in anionic forms (e.g., $\mathrm{H}_{2} \mathrm{AsO}_{4}{ }^{-}, \mathrm{HAsO}_{4}{ }^{2-}$ ) under aerobic conditions with the content 
can account for $65-98 \%$ of total arsenic (Ohtsuka et al., 2013). On the contrary, arsenite takes an electrically uncharged molecule form $\left(\mathrm{H}_{3} \mathrm{AsO}_{3}\right)$ under anaerobic reducing conditions $(\mathrm{Eh}<100 \mathrm{mV} ; \mathrm{pH}<9)$ (Han et al., 2011). The amount of Fe oxides in the soil plays an important role in controlling the concentration of As species in the soil solution; typically, As(V) is strongly adsorbed with metal-(oxyhydr) oxides, whereas As(III) is poorly associated with soil minerals owing to its feature of charge-neutral (Chen et al., 2006; Ehlert et al., 2014); and thus rendering it comparatively effective towards to plants uptake than the $\mathrm{As}(\mathrm{V})$ (Xu et al., 2017). However, it is well recognized that during the drastically aerobic-anaerobic transition within paddy fields, the absorbed As will released into soil porewater (Ohtsuka et al., 2013; Xu et al., 2017). The mobilization of As in flooded paddy fields is because of two main processes. Firstly, the reductive dissolution of iron(oxyhydr) oxides have been triggered by soil flooding which caused the sorbed solid phase arsenic releasing into the liquid phase (Lemonte et al., 2017; Weber et al., 2010; Yamaguchi et al., 2011). Secondly, the adsorbed $\mathrm{As}(\mathrm{V})$ is reduced to $\mathrm{As}(\mathrm{III})$ under the reductive conditions and the latter has a greater tendency to partitioning into the liquid phase than As(V) (Liu et al., 2015; Takahashi et al., 2004). Compared with other terrestrial plant, rice (Oryza sativa L.) is efficient in As uptake and translocation, because of the flooded conditions and highly expressed arsenic transporter ( $\mathrm{Si}$ transporter, aquaporins and phosphate transporters) (Ma et al., 2008; Meharg, 2004; Meharg and Jardine, 2003). Thus, effective measures must be taken to reduce the bio-availability and mobility of As(III) in paddy soil during rice cultivation. 
In current literature, several measures have been proposed for reducing the bio-availability of As in soils, such as amendments stabilization (biochar, natural minerals, etc.) (Kumpiene et al., 2008; Li et al., 2018), electro-kinetics (Balasubramanian et al., 2009), acid flushing (Beiyuan et al., 2017; Tokunaga and Hakuta, 2002), phytoremediation (Gilloaiza et al., 2016; Jankong et al., 2007) and agronomic mitigation strategies (Limmer et al., 2018; Seyfferth et al., 2018). However, those methods are hard to meet the actual demand of paddy fields remediation. Due to either their high-cost (Liu et al., 2018), vast energy requirements (Villen-Guzman et al., 2017), or long treatment times (Wan et al., 2016); above all, high cost (or unsustainability) hinder the application of many technologies in polluted farmland (Bontempi, 2017). Chemical stabilization methods, in particular, have been widely accepted in the remediation of As-contaminated soils because they are relatively cost effective (sustainability) and easy to operate and management. Recently, engineered nanoparticles stabilizer such as zero valent iron (Gil-Díaz et al., 2017; Gil-Díaz et al., 2016) and iron phosphate (vivianite) nanoparticles (Liu and Zhao, 2007) has been proved to be an advanced environmental remediation technologies, which could provide cost-effective solutions to some of the most intractable environmental restore problems due to their large surface areas and high surface reactivity (Zhang, 2003). For the variable valence elements (As), by consideration of regulatory measures (in situ oxidation by chemical amendments) to induction the transformation of As(III) to $\mathrm{As}(\mathrm{V})$ is considered to be a promising approach which can alleviate the associated environmental risks of As in paddy soil (Lin et al., 2017; Suda and Makino, 2016; Xu 
et al., 2017). However, to our knowledge, there are few related studies focused on the induction of As to be transformed into low-effective and low-toxicity forms using oxidants in paddy soil.

Manganese oxides are naturally occurring powerful oxidants that can effectively catalyze the oxidation of $\mathrm{As}(\mathrm{III})$ to $\mathrm{As}(\mathrm{V})$ under natural circumstances (Bruce A. Manning et al., 2002; Ehlert et al., 2014; Han et al., 2011; Lafferty et al., 2010). The As(III) oxidation by manganese oxides can occur across a wide $\mathrm{pH}$ ranged from 4.0 8.2, however, the oxidation rates are deeply associated with their structure, surface charge properties, mineral crystallinity and abundance (Oscarson et al., 1983; Scott and Morgan, 1995). The study conducted by (Bruce A. Manning et al., 2002) showed that $\mathrm{As}(\mathrm{III})$ can be quickly oxidized into $\mathrm{As}(\mathrm{V})$ in the presence of $\mathrm{MnO}_{2}$ with only about $10 \%$ of $\mathrm{As}(\mathrm{III})$ was remined after 10 hours reaction. Besides, another profound and detailed researches conducted by Scott and Morgan (Scott and Morgan, 1995) who found that birnessite $\left(\delta-\mathrm{MnO}_{2}\right)$ can quickly oxidize $\mathrm{As}(\mathrm{III})$ to $\mathrm{As}(\mathrm{V})$, about $80 \%$ of the reaction can be accomplished within $1 \mathrm{~h}$ and this process was accompanied by the release of $\mathrm{Mn}^{2+}$. Apart from the oxidation ability towards to As(III) by manganese oxides, it was also reported that As(III), after being oxidized by Mn-oxides, can subsequently be adsorbed onto the surfaces of $\mathrm{MnOOH}$ (oxidation intermediates) and ferric-(oxyhydr) oxide (Ehlert et al., 2014; Nesbitt et al., 1998); thus the partitioning of As into solution was restrained. Although there are many studies (BA et al., 2002; Ehlert et al., 2014) have been conducted on the oxidation of As(III) by manganese oxides, however, most of these studies are concentrated on pure 
minerals in aqueous solution.

To the best of our knowledges, there are very few related studies on the oxidation of As(III) by synthetic nanostructured- $\mathrm{MnO}_{2}$ in actual paddy soils; especially in the low or medium background Mn concentration soil. In China, it has been reported that the content of $\mathrm{Mn}$ in soil was varied between $10-5532 \mathrm{mg} \cdot \mathrm{kg}^{-1}$ with an average amount of $710 \mathrm{mg} \cdot \mathrm{kg}^{-1}$ (Liu et al., 1983). The Mn concentrations which below the average value of $710 \mathrm{mg} \mathrm{kg}^{-1}$ can be classified as low manganese soil. Recently, a soil incubation experiment conducted by Xu et al (Xu et al., 2017) showed that additions of synthetic Mn oxide (hausmannite) in low background Mn content paddy soils can effectively control the partitioning of As from solid phase to liquid phase due to the oxidation of As(III) However, they only have considered the efficiency of micrometer scale Mn oxides under the laboratory conditions but did not test it under complex field trials. Therefore, we have proposed a hypothesis that the endogenous iron oxides in paddy soil can be used to retain the oxidized As $(\mathrm{V})$ after incorporation with nanostructured manganese oxides under flooded conditions, thereby reducing the bioavailability of As towards to rice. The major objectives of this present study are therefore to (i) investigated the potential of synthetic $\alpha-\mathrm{MnO}_{2}$ nanorods on the control of solid to solution distribution of As under flooded conditions; (ii) determined whether synthetic $\alpha-\mathrm{MnO}_{2}$ nanorods could reduce As uptake into rice grow in paddy soil with low endogenous Mn concentration at fields scales; and (iii) elucidated the associated mechanisms regarding to the reduced of As uptake by rice. 


\section{Material and methods}

158

\subsection{Chemicals and reagents}

All chemicals, including manganese sulfate $\left(\mathrm{MnSO}_{4} \cdot \mathrm{H}_{2} \mathrm{O}\right)$, potassium persulfate $\left(\mathrm{K}_{2} \mathrm{~S}_{2} \mathrm{O}_{8}\right)$, ammonium phosphate $\left(\left(\mathrm{NH}_{4}\right)_{3} \mathrm{PO}_{4} \cdot 3 \mathrm{H}_{2} \mathrm{O}\right)$, urea $\left(\mathrm{CO}\left(\mathrm{NH}_{2}\right)_{2}\right)$, potassium carbonate $\left(\mathrm{K}_{2} \mathrm{CO}_{3}\right)$, hydrochloric acid $(\mathrm{HCl})$, nitric acid $\left(\mathrm{HNO}_{3}\right)$ and sulfuric acid $\left(\mathrm{H}_{2} \mathrm{SO}_{4}\right)$ used in this study were of analytical grade without any further purification.

The $\alpha-\mathrm{MnO}_{2}$ nanorods was synthesized following the protocol previously outlined by(Yu et al., 2013) with minor modification; Briefly, the $\alpha-\mathrm{MnO}_{2}$ nanorods were hydrothermally synthesized using a solution containing a certain amount of $\mathrm{MnSO}_{4} \cdot \mathrm{H}_{2} \mathrm{O}(0.3415 \mathrm{~g}, 2 \mathrm{mmol})$ and $\mathrm{K}_{2} \mathrm{~S}_{2} \mathrm{O}_{8}(0.5434 \mathrm{~g}, 2 \mathrm{mmol})$, the detailed procedures can be found in supplementary material. The obtained $\alpha-\mathrm{MnO}_{2}$ nano materials are a very stable black powdery solid. The powder X-ray diffraction (XRD) patterns of the obtained materials were recorded on a Bruker D8 Advance XRD diffractometer with $\mathrm{Cu}$ Ka radiation (Voltage: 40 kV; Current: 40 mA; Scanning rate: $10 \%$ min). The morphologies of the samples were observed by emission scanning electron microscopy (SEM, Quanta F250, FEI, USA) Ultrapure water $(18.2 \mathrm{M} \Omega \mathrm{cm})$ was used in all experiments, unless otherwise stated. All experimental containers were soaked with $10 \% \mathrm{HNO}_{3}$ overnight and rinsed several times with deionized water before use. 


\subsection{Site characterization and soil sampling}

Chenzhou City lies between $24^{\circ} 53^{\prime}$ and $26^{\circ} 50^{\prime}$ latitudes and between $112^{\circ} 13^{\prime}$ and $114^{\circ} 14^{\prime}$ longitudes(Lei et al., 2015). The research paddy field is located in Dengjiatang $\left(25^{\circ} 36^{\prime} \mathrm{N}, 113^{\circ} 00^{\prime} \mathrm{E}\right)$ village, Su Xian district, Chenzhou City. An As-product factory was located at Dengjiatang in 1992, but it has been out of production since 1999(Lei et al., 2015; Liao et al., 2004; Liao et al., 2005).

Bulk arsenic contaminated soil samples were collected from the plow layers $(0-20 \mathrm{~cm})$. The soil samples were air-dried at room temperature, ground, and passed through a 5-mm nylon sieve. The elementary physicochemical properties were analyzed, and the results were shown in Table S1 in supplementary material.

\subsection{Soil incubation and As sequential extraction experiment}

Soil incubation experiments were designed to explore the effect of $\alpha-\mathrm{MnO}_{2}$ nanorods on the variations of As fractionation in flooded paddy soil. To prepare the $\alpha-\mathrm{MnO}_{2}$ treated samples, $15 \mathrm{~kg}$ sieved soil was weighted carefully and packed into a polyethylene pot $(50 \mathrm{~cm} \times 22 \mathrm{~cm})$. Subsequently, the soil was amended with $\alpha-\mathrm{MnO}_{2}$ nanorods to maintain the rates of $0.2 \%, 0.5 \%, 1.0 \%$ and $2.0 \%$ of soil weight. The pot was first pre-incubated for $24 \mathrm{~h}$ in the dark with soil moisture content being maintained at $70 \%$ field water holding capacity. After that, the pots were incubated at $25^{\circ} \mathrm{C}$ in the growth chamber, with daily additions of ultra-pure water to maintain the water level of $3 \mathrm{~cm}$ above the soil surface.

After 90 days, the soil samples were collected from the surface $(0-20 \mathrm{~cm}$ depth) 
of the soil profile. After being air-dried at ambient temperature, obtained soil will first ground to pass through $1 \mathrm{~mm}$ screen, and then ground again using agate mortar and passed through $0.15 \mathrm{~mm}$ screen prior to analysis. A sequential As fractionation schemes was employed to determine the operationally defined As fractionation(Van et al., 2003; Wu et al., 2006). The detail operation procedure was described in supplementary material. (Table S2). All the treatments and extractions procedures were run in triplicates unless stated otherwise. The extraction efficiency of arsenic fractionation was presented in Table S3.

\subsection{Pot experiment designs}

The pot experiment was carried out in a greenhouse of Hunan agricultural university. Firstly, $15.0 \mathrm{~kg}$ homogenized arsenic contaminated soil was packed in each polyethylene pot with a height of $50 \mathrm{~cm}$ and a diameter of $22 \mathrm{~cm}$. Ammonium phosphate $\left(\left(\mathrm{NH}_{4}\right)_{3} \mathrm{PO}_{4} \cdot 3 \mathrm{H}_{2} \mathrm{O}\right)$, urea $\left(\mathrm{CO}\left(\mathrm{NH}_{2}\right)_{2}\right)$, potassium carbonate $\left(\mathrm{K}_{2} \mathrm{CO}_{3}\right)$, were added to each pot as basal fertilizers at dosage of 4.29, 2.93, and $3.30 \mathrm{~g}$ for N, P, and

$\mathrm{K}$ supply, respectively. Then the soil was amended with $\alpha-\mathrm{MnO}_{2}$ nanorods at rates of $0.2 \%, 0.5 \%, 1.0 \%$ and $2.0 \%$ of soil weight. Each pot was then saturated with distilled water and drained down to an equilibrium state for 7 days under natural conditions. All the treatments were triplicated and randomly arrangement and three blank controls (without $\alpha-\mathrm{MnO}_{2}$ nanorods addition) were provided.

The rice seeds (O. sativa $L$ Yuzhenxiang, obtained from Hunan Rice Research Institute) were disinfected in $30 \% \mathrm{H}_{2} \mathrm{O}_{2}$ solution for 10 minutes, followed by thorough 
washing with deionized water and soaking in deionized water for $24 \mathrm{~h}$. Rice seeds were germinated in moist vermiculite trays until the three-leaf stage and then transplanted into pots. During the whole growth period, all pots were irrigated with distilled water daily to maintain the water level of $3 \mathrm{~cm}$ above the soil surface. Porewater samples were collected at a 15-days interval after tillering stage (after 45 days) using a porous fiber tube. The $\mathrm{pH}, \mathrm{Mn}$ and As concentrations in soil solutions were analyzed. Rice was harvested at the 105th day. At each growth stage (tillering, heading and maturing stages) rice plants were collected, digested, and then the concentrations of $\mathrm{Mn}$ and As in the organs (roots, stems, leaves, husk and grains) of rice plants were analyzed.

\subsection{Field application experiment designs}

\subsubsection{Experimental design}

The field experiment has carried out in May 2013 at a paddy field in Dengjiatang, Chenzhou City, Hunan Province, $\left(25^{\circ} 36^{\prime} \mathrm{N}, 113^{\circ} 00^{\prime} \mathrm{E}\right)$. The paddy fields were divided into $1.5 \mathrm{~m} \times 1.5 \mathrm{~m}$ sub-plots with a 40 -cm buffer zone between each. Before rice planting, the top soil $\left(0-20 \mathrm{~cm}\right.$ depth) was subject to manual plowing. $\alpha-\mathrm{MnO}_{2}$ nanorods was then added into the soil at a rate of $0.2 \%, 0.5 \%, 1.0 \%$ and $2.0 \%$ of soil weight $(0-20 \mathrm{~cm})$, respectively, and thoroughly mixed with top soil. All treatment was conducted in triplicate with a completely randomized factorial design, and three blank controls (without $\alpha-\mathrm{MnO}_{2}$ nanorods addition) were provided. Each plot was then let to equilibrium for 7 days under natural conditions. Rice cultivars used in the pot 
experiment (Yuzhenxiang) were also used in the field experiment. Rice seedlings were transplanted after germination for 30 days (on June 6, 2013) and harvested on September 30, 2013. To facilitate in situ sampling of pore water, during the growth of rice, 'Rhizon' soil solution samplers (Rhizon Research Products, Wageningen, The Netherlands) were buried in each plot while the rice was transplanted. During the whole growth period, water layer of about $3.0 \mathrm{~cm}$ above the topsoil of the paddy field was maintained. The other cultivation methods were the same as the local paddy cultivation methods until the rice has matured.

\subsubsection{Sampling and, analyses}

Extractions of pore water were conducted in the tillering stage (45 days after germination) and were extracted every 15 days during the last period (days 45-105). The soil solution $\mathrm{pH}$ was recorded at the same time intervals as for pore water sampling. The concentrations of $\mathrm{Mn}$ in pore water were measured in acidified subsamples by inductively coupled Plasma optical emission spectrometer (ICP-OES, PerkinElmer Optima 8300, USA). As concentrations in soil pore water was determined by atomic fluorescence spectrometer (AFS-920, Beijing Titan Instruments Co., Ltd.). At each specifically growth period, the plants sample was collected at the tillering, heading and maturing stages. Rice plant samples were separated into roots, stems, leaves and grain. And washed three times using distilled water, the cleaned plant samples were placed in an oven at $105^{\circ} \mathrm{C}$ for $2 \mathrm{~h}$ and dried at $70^{\circ} \mathrm{C}$ for 3 days to constant weight, and then ground to pass a 100-mesh sieve with a micro plant 
grinding machine.

The method for total As digestion and determination in rice plants was conducted following the protocol of GB/T 5009.11-2003 which issued by Ministry of Environmental Protection (MEP) of China (Geng et al., 2017). Typically, $1.0 \mathrm{~g}$ of dry rice sample was digested using a mixture of acids $\left(4: 1 \mathrm{HNO}_{3}: \mathrm{HClO}_{4}, \mathrm{v} / \mathrm{v}\right)$ at $180^{\circ} \mathrm{C}$ on a graphite digestion furnace. After digestion, the solution will let to cool down to ambient temperature and made to $25 \mathrm{~mL}$ using UP water, each digested solution will store in $50 \mathrm{~mL}$ polyethylene bottle at $4^{\circ} \mathrm{C}$ before analysis. As concentrations in plants tissues will determined by atomic fluorescence spectrometer (AFS-920, Beijing Titan Instruments Co., Ltd.), Mn concentrations will measure by ICP-OES (Optima8300 PerkinElmer). For quality assurance and quality control purposes, blanks and standard plant reference material (shrub branches and leaves GBW07603 (GSV-2), rice material (GBW10010 (GSB-1) were obtained from China Standard Materials Research Center, Beijing, P.R. China and digested along with the unknown samples and used for the QA/QC program. All the glassware was washed with detergent firstly, soaked with $20 \% \mathrm{HNO}_{3}$ solution for $24 \mathrm{~h}$, and then rinsed with UP water for three times before use.

\subsection{Statistical analyses}

All statistical analyses were performed with SPSS 22.0 software (SPSS Inc., Chicago, IL, USA). Differences between the control and treatment samples were determined using ANOVA and Tukey multiple comparisons analysis with $p<0.05$ 
indicating statistical significance. Correlations were obtained by Pearson correlation coefficient in bivariate correlations.

\section{Results}

\subsection{Characterization of synthesized $\alpha-\mathrm{MnO}_{2}$ nanorods}

The x-ray diffraction (XRD) pattern and scanning transmission electron microscopy (SEM) images of the synthesized $\alpha-\mathrm{MnO}_{2}$ nanorods are shown in Fig.S1, Fig.S2, respectively. It can be seen that manganese dioxide is clustered; the structure is uniformly well dispersed spherical agglomerate particles. High-magnification SEM images showed that the $\alpha-\mathrm{MnO}_{2}$ is an urchin-like spherical with a diameter of 1-1.5 $\mu \mathrm{m}$, which consists of several straight and radially grown nanorods with uniform diameter around 30-40nm (Fig.S2a, b). The synthesized $\alpha-\mathrm{MnO}_{2}$ nanorods has an obvious characteristic diffraction peak in the XRD pattern (Fig.S1), which indicated that the high crystallization degree of nanostructured manganese dioxide, and the characteristic peak was also in agreement with the standard data given in its JCPDS card (24-0072).

\subsection{Effects of different amount of $\alpha-\mathrm{MnO}_{2}$ nanorods on distribution of arsenic}

\section{fractionation}

The As sequential extraction procedure is widely used to evaluate As distribution within soil fractionation, which can help us to understand the mobility and 
bioavailability of As in soil(Jin et al., 2011; Wenzel et al., 2001; Zhang et al.,

302 2017). The effect of different dosages of $\alpha-\mathrm{MnO}_{2}$ nanorods on the distribution and 303 percentages of Arsenic fractionation in paddy soil are presented in Fig.1. In general, the application of $\alpha-\mathrm{MnO}_{2}$ amendment increased the residual fractionation and reduced the effective forms of As to some extent, indicating that $\alpha-\mathrm{MnO}_{2}$ can effectively control the bioavailability of As in soil. As shown in Fig.1, in the treated and untreated soil, loosely bound As comprised the smallest proportions of all the As fractionation $(<3 \%)$; what's more, the content of loosely bound As in the soil with $1.0 \% \mathrm{MnO}_{2}$ treatment was significantly lower than that in other treatment. However, residual fractionation contained the most proportions of As (about 50\%), whether or not to add $\alpha-\mathrm{MnO}_{2}$ into soil. Besides, proportions of residual As in the $1.0 \% \mathrm{MnO}_{2}$ treated soil was increased to $57.08 \%$ which indicated that the addition of with the increase of concentration, Ca-As content showed an obviously decreasing trend, which indicated that the addition of $\alpha-\mathrm{MnO}_{2}$ in paddy soil has a certain inhibitory effect on the binding of As and Ca. 


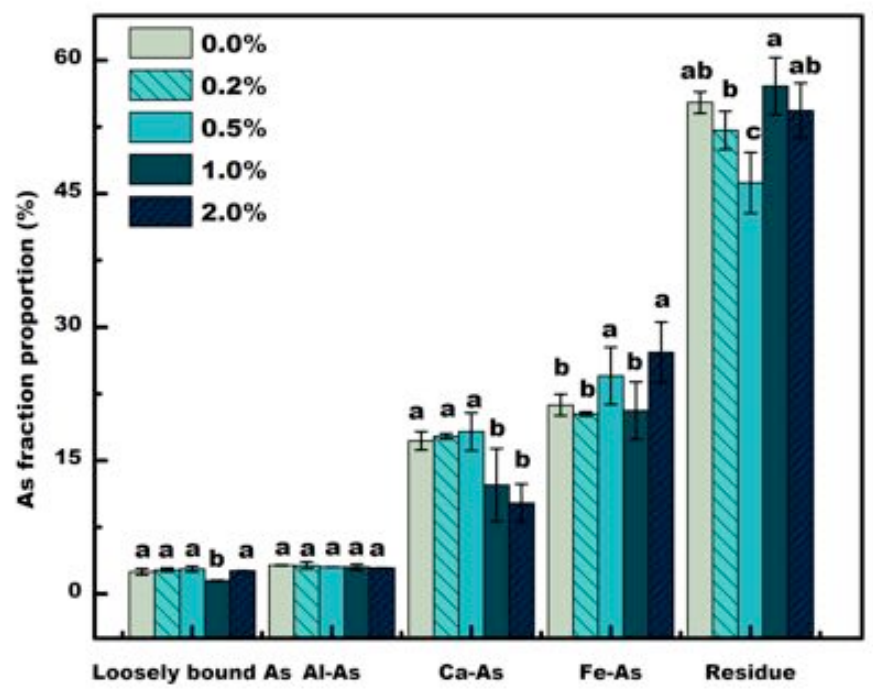

Fig.1. Fraction distributions of arsenic in paddy soil amended with different amounts of $\alpha-\mathrm{MnO}_{2} ;$ different letters indicate significant difference between different treatments $(P<0.05)$, arsenic fraction tested was separately from each other.

For Fe-bound As, there was no regular change of Fe-As in the soil after the addition of $\alpha-\mathrm{MnO}_{2}$. However, it can be seen that the content of Fe-As in soils increased to $24.53 \%$ and $27.16 \%$ at rates of $0.5 \%$ and $2.0 \%$, respectively. However, at dosages of $0.2 \%$ and $1 \%$, the amount of Fe-As in the soil has reduced, and the addition of $1 \%$ was more obvious, which was $20.62 \%$.

\subsection{Pot experiments}

\subsubsection{Effect of $\alpha-\mathrm{MnO}_{2}$ on the dynamic $\mathrm{pH}$ variations of soil solution}

The dynamics variations of $\mathrm{pH}$ in the pore water during growth of rice under treatments of different amounts of $\alpha-\mathrm{MnO}_{2}$ were presented in Fig.S3. In general, during the whole growth stage (45-105 days), the soil pore water $\mathrm{pH}$ either increased to or remained stable in the near-neutral range after amended with different amounts of $\alpha-\mathrm{MnO}_{2}$. The $\mathrm{pH}$ range of the soil solution was around 7.36-7.55 for the 45 th day, which was higher than the $\mathrm{pH}$ (7.25) of CK (Control treatments). The highest $\mathrm{pH}$ 


\subsubsection{Effect of $\alpha-\mathrm{MnO}_{2}$ on the dynamic variations of $\mathrm{As}$ and $\mathrm{Mn}$ in pore water}
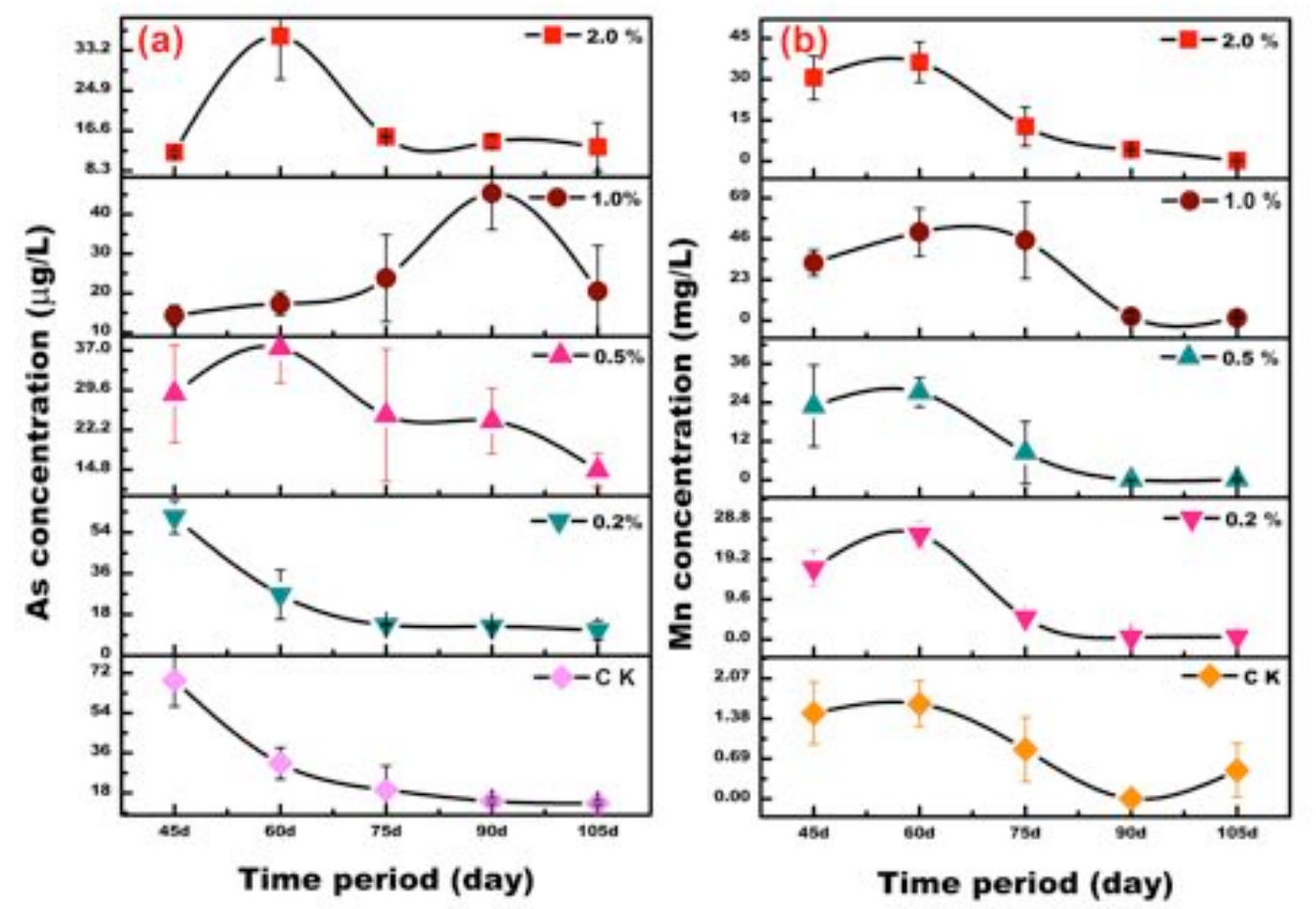
arsenic and manganese content in pore water at different growth period of rice is shown in Fig.2. Different reduction patterns of arsenic in soil pore water were observed among with different treatments. Regardless of the addition of $\alpha-\mathrm{MnO}_{2}$, the

Fig.2. Dynamics variations of pore water $\mathrm{As}$ (a) and $\mathrm{Mn}$ (b) in the $\alpha-\mathrm{MnO}_{2}$ treatments throughout the rice cultivation period. Data are means $\mathrm{SE}(\mathrm{n}=3)$.

After treatments with different dosage of $\alpha-\mathrm{MnO}_{2}$ the dynamic variation of arsenic content in soil pore water of CK was decreased from the 45th day to the 105 th 
day, and reaching the minimum value of $13.26 \pm 0.94 \mu \mathrm{g} \cdot \mathrm{L}^{-1}$ at the 105 th day; possibly due to the adsorbed by newly formed endogeneity amorphous iron oxides (Amstaetter et al., 2012; Cismasu et al., 2015). However, compared with CK, the content of arsenic in pore water after adding $\alpha-\mathrm{MnO}_{2}$ with different dosages decreased markedly at the 45th day. All treatments showed an obvious dosage dependent reduction trend of arsenic in soil pore water. Similarly, the decline trend was observed between CK and $0.2 \%$ treatments; however, with the increasing of dosages the content of arsenic began to rebound after 45 days. Arsenic concentrations peaked at 60 days of reaction at $0.5 \%$ treatments; 90 day for $1.0 \%$ treatments and 60 day of $2.0 \%$ treatments. In spite of fluctuation, what worth affirming was that arsenic in soil pore water still decreased to a constant level $\left(10.94-14.69 \mu \mathrm{g} \cdot \mathrm{L}^{-1}\right)$ at the end of rice cultivation period (90-105 day), except for $1 \%$ treatment, nearly 2-fold $\left(20.49 \mu \mathrm{g} \cdot \mathrm{L}^{-1}\right)$ increased in porewater As was observed during 90-105 day.

Unlike As, $\alpha-\mathrm{MnO}_{2}$ treatments increased porewater Mn levels (Fig.2b), four treatments $(0.2 \%, 0.5 \%, 1.0 \%$ and $2.0 \%)$ showed that substantial increased in the porewater Mn concentration at the 45th day, whereas Mn concentration in the CK soil porewater remained low level throughout the whole cultivation period (45-105 days). What's more, Mn concentrations kept increasing after another 15 days; with 17-33 folds augment compared with that of control soil. This is more likely coupled with the enhanced dissolution of manganese resulting from oxidation of $\mathrm{As}(\mathrm{III})$ to $\mathrm{As}(\mathrm{V})$ by manganese oxide (Xu et al., 2017; Z et al., 2017). Yet, effluent Mn(II) concentrations in soil porewater began to drop at the 60th day, with concentrations declining to a 
374 all the four treatments, $1.0 \%$ retained the highest porewater Mn dissolution rate

375 compared with other treatments during day 45-75 days and reaching a peak of 49.77

$376 \mathrm{mg} \cdot \mathrm{L}^{-1}$ on the $60 \mathrm{th}$ day. In the meantime, however, the other three treatments have

377 already dropped to low levels $\left(5.2-12.6 \mathrm{mg} \cdot \mathrm{L}^{-1}\right)$.
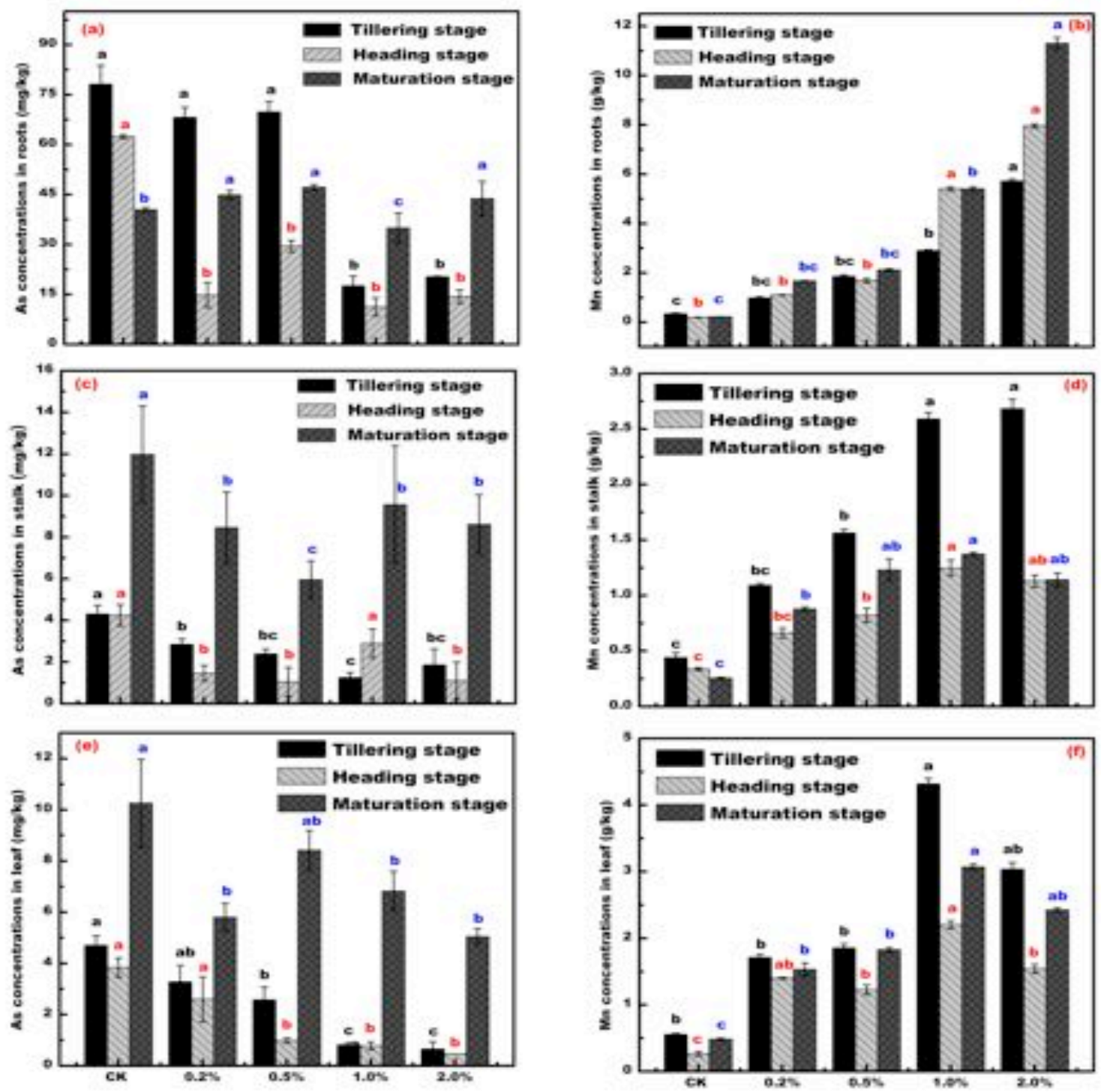

Fig.3. As and Mn concentrations in the root $(a, b)$, straw (c, d), leaf (e, f) in the $\alpha-\mathrm{MnO}_{2}$ treatments; Data are 
means SE $(n=3)$, different letters indicate significant difference between different treatments $(P<0.05)$, significant tests are separate from each other (black letter indicates tillering stage, red letter indicates heading stage, blue letter indicates maturation stage)

The contents of As and $\mathrm{Mn}$ in different parts of rice at various growth stages are shown in Fig.3. Three different rice growth stages (Tillering, heading and mature stage) were selected to estimate the efficiency of $\alpha-\mathrm{MnO}_{2}$ in controlling the accumulation of $\mathrm{As}$ and $\mathrm{Mn}$ in rice. In general, regardless of the addition of $\alpha-\mathrm{MnO}_{2}$, the distribution pattern of arsenic in rice roots, stems and leaves follows the order of roots $>$ stems $>$ leaves. However, with the addition of $\alpha-\mathrm{MnO}_{2}$, the arsenic content in various parts of rice at each growth period was reduced to varying degrees compared with the CK. That is, the addition of $\alpha-\mathrm{MnO}_{2}$ can effectively impede the migration of arsenic to rice plants. In $\alpha-\mathrm{MnO}_{2}$ treatments, root As was decreased by $10.63-77.51 \%$ at tillering stage (Fig.3a), 52.71-81.94\% at heading stage compared to the control. However, the interesting thing is that the reduction rate of arsenic in the mature stage was much lower than that of the other two growth period, which was indicated that the heading and tillering stage may be the key time period to control the transportation and migration of As (Li et al., 2015; Zheng et al., 2011).

On the contrary, the distribution pattern of Mn content in rice roots was clearly different from that of As in rice. Compared with CK, the Mn content in various parts of rice plants has significantly increased $(p<0.05)$ at different growth stages after addition of $\alpha-\mathrm{MnO}_{2}$ and the increasing trend was obviously dosage dependent, which illustrated that the order of $\mathrm{Mn}$ in roots, stems and leaves of rice was: $2.0 \%>1.0 \%>$ $0.5 \%>0.2 \%>\mathrm{CK}$ (Fig. $3 \mathrm{~b}$ ). The overall Mn concentration in rice roots was increased by 1.9-15.87 times at tillering stage, 4.58-39.46 times at heading stage and 6.5-49.89 
times at the mature stage, respectively.

Although $\alpha-\mathrm{MnO}_{2}$ treatments were effective in reducing and accumulating of As and $\mathrm{Mn}$ in rice roots; their effects, however, on As, Mn transportation in the straw and leaf was less satisfactory. For the re-distribution of As in rice stalk and leaf, regardless of the addition of $\alpha-\mathrm{MnO}_{2}$ and rice growth period sequences, the higher accumulation efficiency were observed at mature stage for both stalk and leaf; which indicated that mature stage were the crucial period for the translocation and migration of As in rice (Fig.3ce). However, the accumulation of Mn in stalks and leaves showed different patterns (Fig.3df), rice tended to accumulate more Mn during tillering stage, which was probably due to the enhanced dissolution of $\mathrm{Mn}$ in soil porewater at early stages (45-60 days) of rice growth after amended with $\alpha-\mathrm{MnO}_{2}$ nanorods.

In addition, the observed results also implied that the re-distribution of As in rice part did not interfered by the added $\alpha-\mathrm{MnO}_{2}$ after the tillering stage and this phenomenon was less time-dependent; which also confirmed that the As was sequestered in rice roots and thus the subsequent influx of As into other rice parts was restrained (Fig.3ce).

The content of As and $\mathrm{Mn}$ in brown rice and husk can further prove this phenomenon (Fig.4). The addition of $\alpha-\mathrm{MnO}_{2}$ Nano-rods significantly reduced the total arsenic content in brown rice and husk $(\mathrm{p}<0.05)$, while the Mn content was significantly increased $(\mathrm{p}<0.05)$. Compared with $\mathrm{CK}$, the contents of total arsenic in the husks decreased by $36.4 \%, 24.0 \%, 12.6 \%$ and $15.5 \%$, respectively. Furthermore, the content of total arsenic in brown rice was decreased by $17.8 \%, 36.4 \%, 65.4 \%$ and 
428 effectively prevent arsenic uptake by brown rice. Meanwhile, Mn concentrations in

429 rice husk and brown rice increased in a dosage dependent way, which demonstrated

430 that the $\mathrm{Mn}$ concentrations increased with increasing dosages of $\alpha-\mathrm{MnO}_{2}$ nanorods.

431 The content of $\mathrm{Mn}$ in the husk increased by $55.8 \%, 79.3 \%, 102.0 \%$ and $133.3 \%$,

432 respectively; and the content of $\mathrm{Mn}$ in brown rice increased by $148.7 \%, 174.6 \%$,

$433 \quad 295.5 \%$ and $310.4 \%$, respectively (Fig.4).

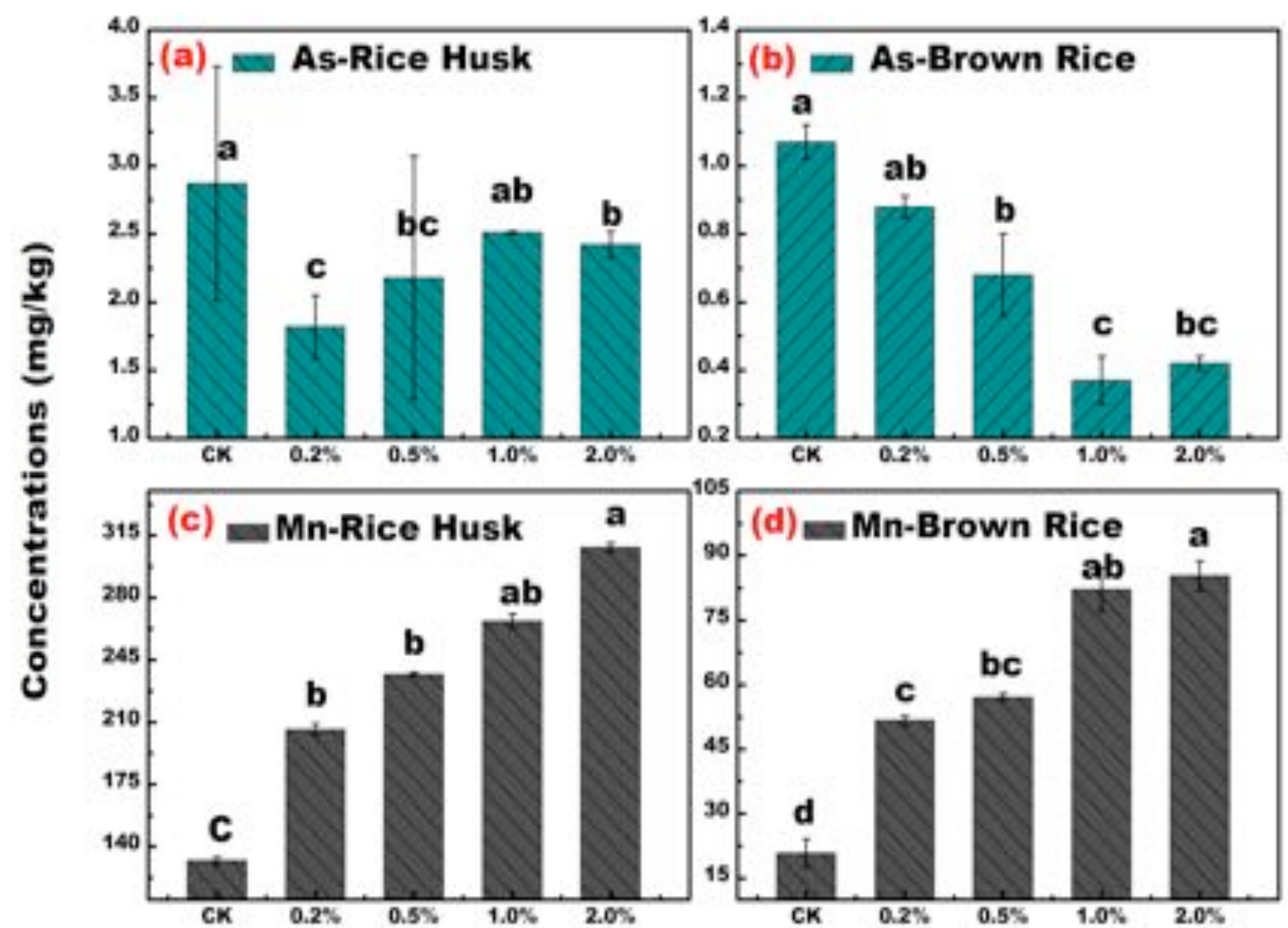

Treatments

434 Fig.4 Concentrations of As and Mn in rice husk and brown rice (Pot experiment),(a) As-rice 435 husk, (b) As-brown rice,(c) Mn-rice husk,(d) Mn-brown rice; Data are means SE (n= 3), 436 different letters indicate significant difference between different treatments $(P<0.05)$. 


\subsubsection{Relationships between As and Mn concentration in rice plants parts under} different growth stages rice (Fig.S4) and different growth stages (Fig.5), we performed a correlation analysis; and the results were presented in Fig.S4 and Fig.5 The concentration of As showed an obviously significant negative correlation $(p<0.05)$ with the amount of $\mathrm{Mn}$ in the rice, indicating that the As content of rice plants decreased significantly with the increase of $\mathrm{Mn}$ concentrations. And this also indicated that the application of $\alpha-\mathrm{MnO}_{2}$ nanorods was extremely effective at decreasing the available As in the soil

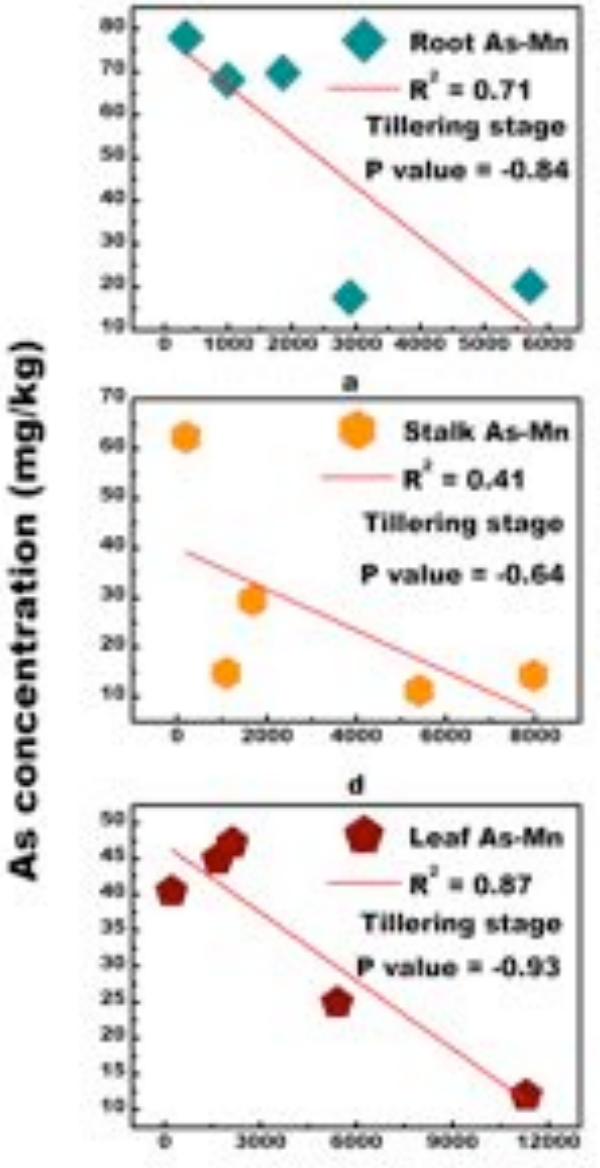

9
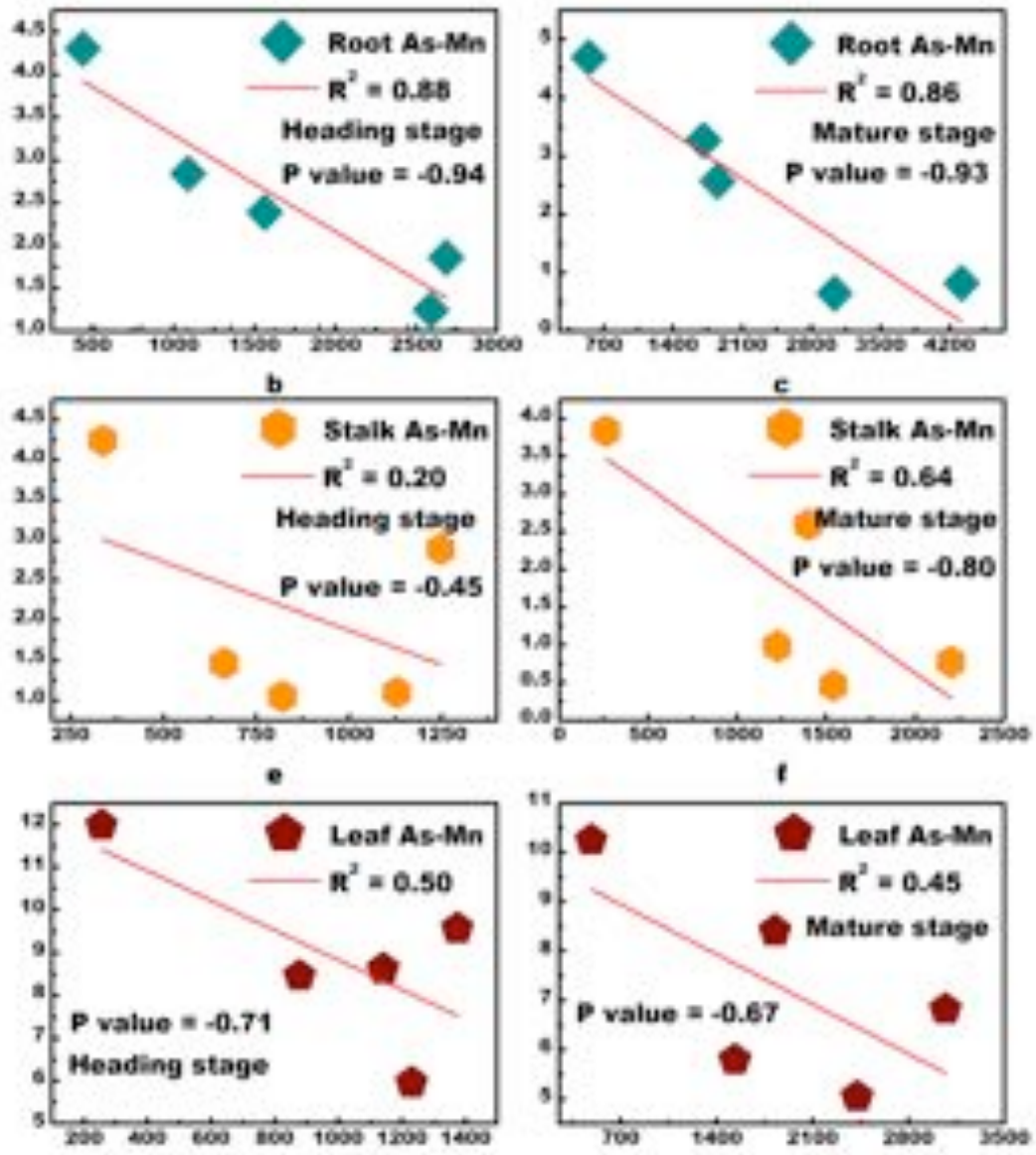

h

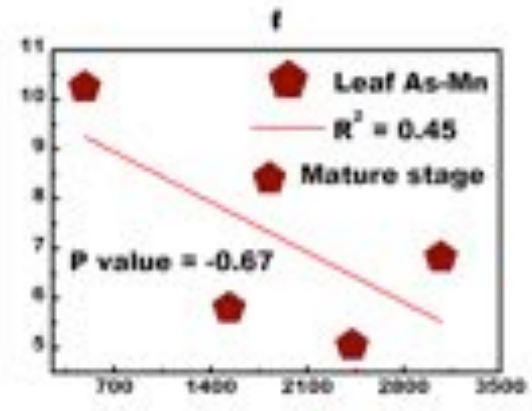

1

\section{Mn concentration ( $\mathbf{m g} / \mathbf{k g}$ )}

Fig.5. Relationships between As and Mn concentration in rice plants during different growth stage (a, b, c, 
In the meantime, the relationships between $\mathrm{As}$ and $\mathrm{Mn}$ in different rice parts at 449 different growth stages were also analyzed, and the correlations were presented in 450 Fig.5, as can be seen from the above picture, overall As and Mn correlations in 451 various parts showed obviously negative correlations. Especially for root As and Mn, 452 their correlation showed higher $\mathrm{R}^{2}$ value compared with other two parts, regardless of 453 the growth stages $\left(\mathrm{R}^{2}=0.71-0.88, p<0.05\right.$; Fig.5abc). In contrast, although at certain 454 growth stages, the As and $\mathrm{Mn}$ in rice parts showed extremely high significance; their 455 overall relationships in stalks $\left(\mathrm{R}^{2}=0.20-0.63\right.$; Fig.5def $)$ and leaves $\left(\mathrm{R}^{2}=0.44-0.87\right.$; 456 Fig.5ghi), however, were poor than roots As-Mn. 

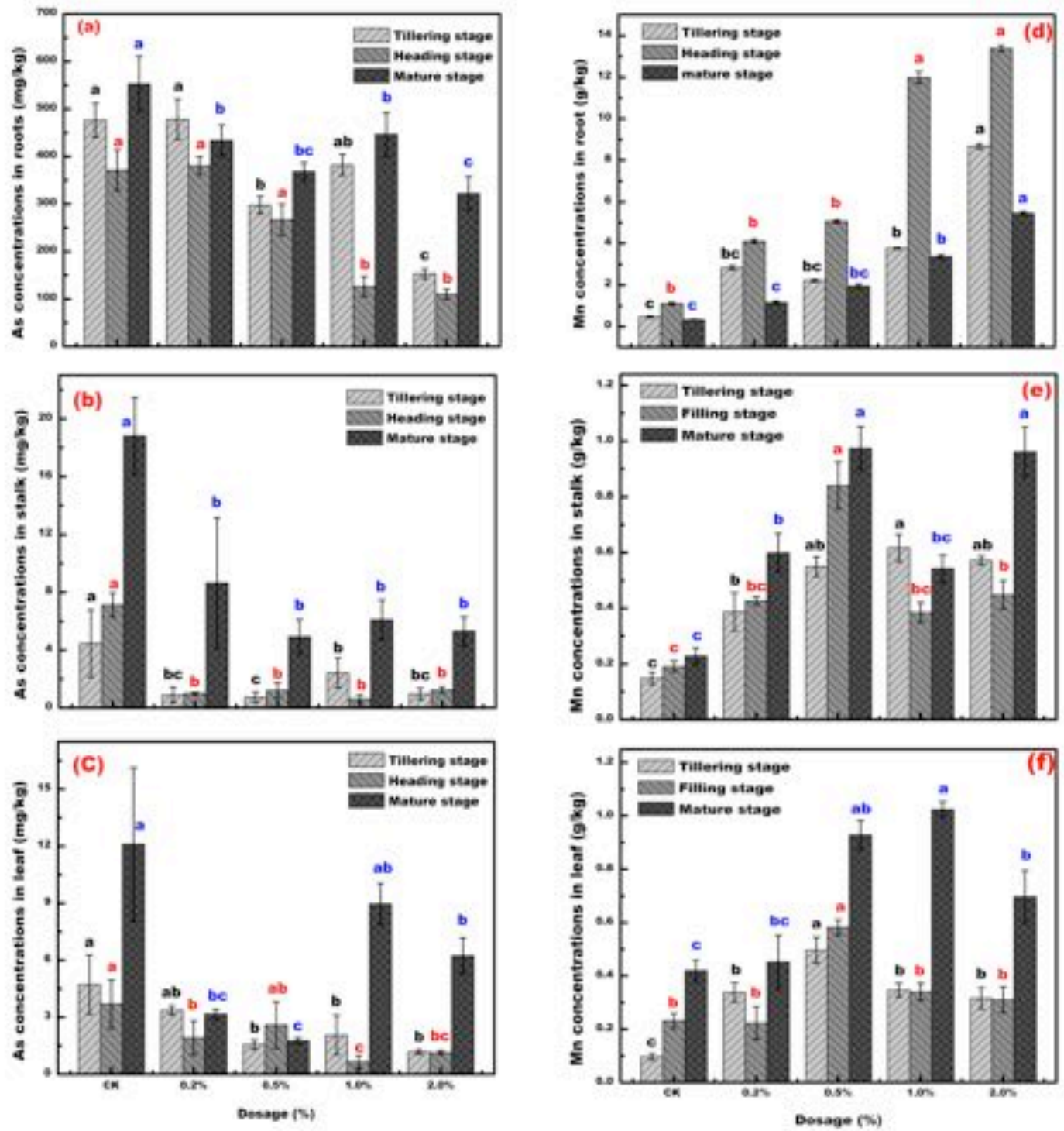

Fig.6. As and Mn concentrations in the root $(a, d)$, straw $(b, e)$, and leaf $(c, f)$ of rice in the $\alpha-\mathrm{MnO}_{2}$ treatments (Field application); Data are means SE $(n=3)$, different letters indicate significant difference between different treatments $(P<\mathbf{0 . 0 5})$, significant tests are separate from each other (black letter indicates tillering stage, red letter indicates heading stage, blue letter indicates maturation stage)

Previous studies have shown that the addition of $\alpha-\mathrm{MnO}_{2}$ nanorods in arsenic-contaminated soil can effectively control the transport of arsenic from soil to rice in pot experiments. This result provides a theoretical basis for the application of $\alpha-\mathrm{MnO}_{2}$ nanorods in field trials. With this in mind, field trials were designed to 
467 further evaluate the effectiveness of $\alpha-\mathrm{MnO}_{2}$ nanorods in controlling the mobility and 468 bio-availability of arsenic in soil-rice interfaces under complex natural systems. The 469 content of arsenic and manganese in different parts of rice at various stages in the 470 field experiment was shown in Fig.6. With the addition of $\alpha-\mathrm{MnO}_{2}$ nanorods, the 471 arsenic content in various parts of rice at each period was reduced to varying degrees 472 compared with the CK group (Fig.6b). It was also can be seen that the arsenic 473 concentration in rice roots was much higher than that in the stalks and leaves. 474 Furthermore, the similar results have been observed in stalks and leaves compared 475 with pot experiment, in which rice tended to accumulate more As at mature stage. 476 And the observed results also indicated that most of the As was sequestered in rice 477 roots (Fig.6bc). Meanwhile, after treatments with different amounts of $\alpha-\mathrm{MnO}_{2}$ 478 nanorods, the content of $\mathrm{Mn}$ in various parts of rice plants increased significantly 
$(p<0.05)$ at different growth periods compared with the CK. And this result was consistent with the results obtained in the pot experiment, which also proved that the $\alpha-\mathrm{MnO}_{2}$ nanorods can indeed reduce the bio-availability of arsenic in soil. After treatment with $\alpha-\mathrm{MnO}_{2}$ nanorods, total As content in brown rice and husk was significantly reduced (Fig.7; p $<0.05$ ). Arsenic content in the husk of CK was $3.06 \pm 0.41 \mathrm{mg} \cdot \mathrm{kg}^{-1}$ and $0.96 \pm 0.08 \mathrm{mg} \cdot \mathrm{kg}^{-1}$ in brown rice. Compared with $\mathrm{CK}$, the contents of total As in husks decreased by $60.5 \%, 79.6 \%, 65.7 \%$, and $56.9 \%$, respectively; and the content of total As in brown rice was decreased by $61.5 \%$, $60.4 \%, 43.4 \%$, and $77.1 \%$, respectively. Among them, the lowest content

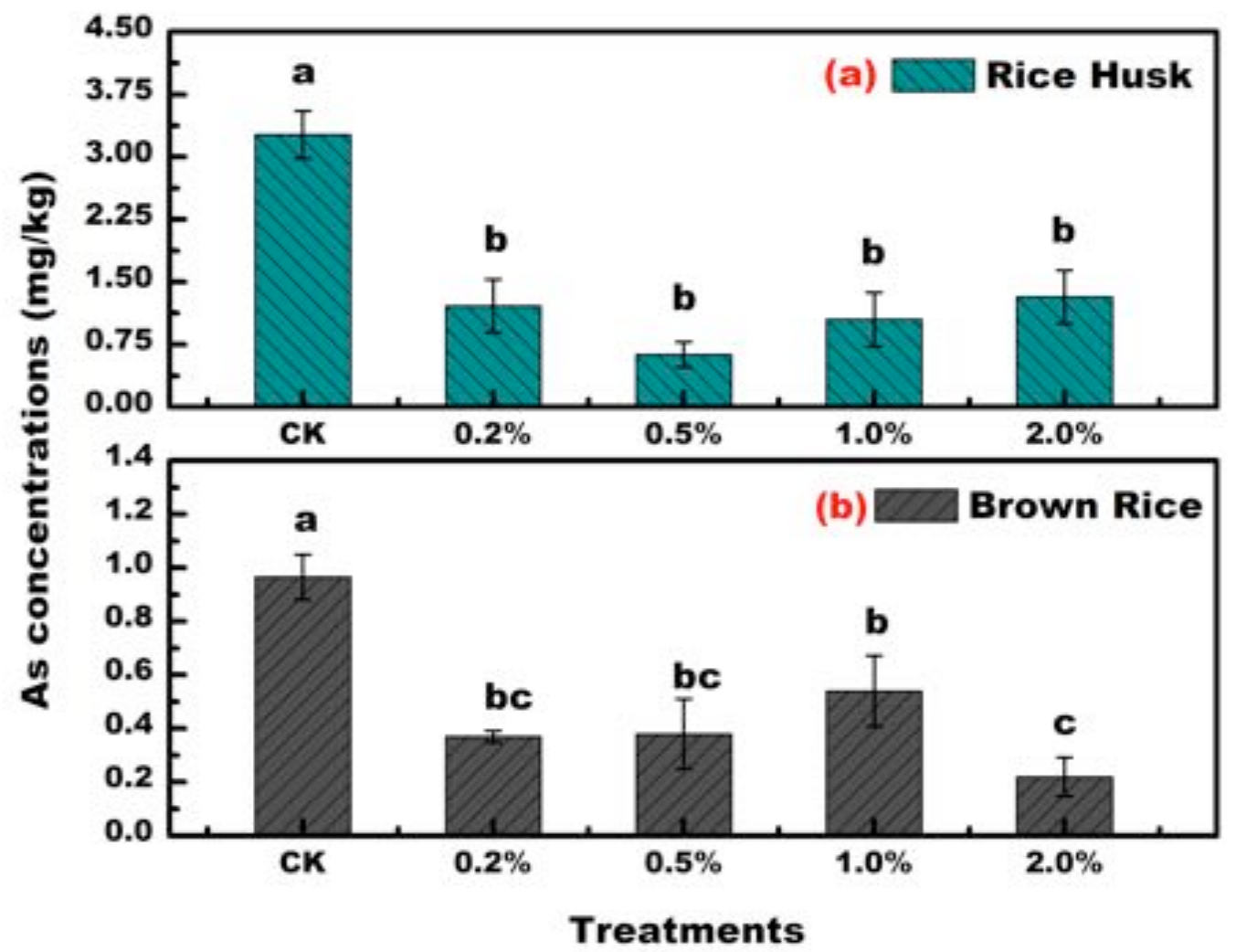

$\left(0.22 \mathrm{mg} \cdot \mathrm{kg}^{-1}\right)$ of As in brown rice was obtained under the condition of $2.0 \%$ treatments. 


\section{Discussion}

494

495

496

497

498

499

500

501

502

\subsection{Effects of different dosages of $\alpha-\mathrm{MnO}_{2}$ nanorods on the solid-liquid partitioning of As in paddy soil}

Since long is it established that the toxicity, activity and bioavailability of As in paddy soil are closely related to its presence in the soil (Yamaguchi et al., 2011). The hazards of As in soil are not only related to its content, but also related to its effectiveness in the soil and its associated binding forms (classification). In the present study, a 90d soil incubation experiment combined with sequential extraction procedure, therefore, was conducted to study the arsenic fractionation transformed in soil under flooded conditions after amended with $\alpha-\mathrm{MnO}_{2}$ nanorods; because it can furnish us an indication for the mobility and bioavailability of As in paddy soil after amended with $\alpha-\mathrm{MnO}_{2}$ nanorods. As can be draw from the above results (Fig.1), after treatment with different amounts of $\alpha-\mathrm{MnO}_{2}$ nanorods the content of effective As decreased with the increasing of residual As and insoluble binding As (Ca-As and Fe-As), indicating that supplementation of $\alpha-\mathrm{MnO}_{2}$ nanorods can effectively control the bio-availability of As in soil and reduced the associated influx of As into rice plants. Generally, loosely bound As (water soluble and exchangeable As) are highly bio-availability, and they are easily absorbed by organisms, resulting in greater toxicity. The Fe-As and other encapsulated state As are not easily absorbed by organisms and enter the water body, their harmfulness is relatively low. Fe-As, Al-As bind closely to soil, their toxicity to organisms are generally less than Ca-As. 
514 (Herreweghe et al., 2003)found that water-soluble As and exchangeable As are 515 soluble As in the soil or As adsorbed on the surface of soil particles, which accounts

516 for less than 3\% of total As. Similar results have been observed in our experiment, the 517 proportion of loosely bound As in the soil was less than $3 \%$ regardless of the addition 518 of $\alpha-\mathrm{MnO}_{2}$ nanorods, which indicated that the mobilization pool of As in paddy soil 519 depends on other forms. Thus, the content of binding As (such as Fe-As, Al-As) may 520 be the most contributing component in soil. Under aerobic conditions, $\mathrm{As}(\mathrm{V})$ is 521 strongly adsorbed on most mineral constituents, including Fe and Al(hydr)oxides 522 (Goldberg, 2002) whereas, arsenite is more mobile because of its poor affinity for mineral surfaces (Han et al., 2011). Manganese oxide has long be regarded as natural 524 occurring powerful oxidants (Han et al., 2011; Ren et al., 2013), which can rapidly convert $\mathrm{As}(\mathrm{III})$ to $\mathrm{As}(\mathrm{V})$ over the $\mathrm{pH}$ range of $4 \sim 8.2$ under natural conditions (Bruce A. Manning et al., 2002). In the present study, in order to simulate an authentic rice growing environment, the soil have been flooded with water along with the whole 528 incubation period. It is well accepted that incubation under flooded conditions can cause solid As to be distributed to liquid phase(Lemonte et al., 2017; Xu et al., 2017), in which the dominating As species was arsenite ; so As can be re-mobilized into soil when $\mathrm{As}(\mathrm{V})$ is reduced to $\mathrm{As}(\mathrm{III})$. In spite of this circumstance, as can be seen from 532 the Fig.1, the content of Fe-As still increased after treatment with $0.5 \%$ and $2.0 \%$ of $\alpha-\mathrm{MnO}_{2}$ nanorods, which proved that the increased binding state As was more likely due to the oxidation of $\mathrm{As}(\mathrm{III})$ into $\mathrm{As}(\mathrm{V})$ by $\alpha-\mathrm{MnO}_{2}$ nanorods and subsequently resulted to the enhanced adsorption onto ferric(hydr)oxides and Al mineral. The 
subsequently re-allocation of As into the soil solution was, thus effectively reduced. Besides, the content of Ca-As was decreased with an increase in the associated residual As at the dosage of $1 \%$, which indicated that the other encapsulated As fractionation was also transformed to less effective forms.

Combined the obtained results in soil incubation experiments, which can provide us with a reliable theoretical basis for our subsequent experiment. The hypothesis of the present study was proposed that in the rice rhizosphere micro-environment, addition of $\alpha-\mathrm{MnO}_{2}$ nanorods can affect the chemical speciation of As in the soil solution through in situ oxidation which in turn affect the bio-availability and mobility of As for rice uptake. As already discussed in soil incubation experiment, the partitioning of As into the soil solution was significantly controlled by As fractionation transformed. This part of observed results can be further proved by the dynamic monitoring of As variations in soil solution (Fig.2ab). As can be seen from Fig.2a, the content of porewater As was significantly decreased as a dosage dependent way at the 45th day with the increasing content of $\alpha-\mathrm{MnO}_{2}$ nanorods. And during the whole growth stages (45-105 days), in spite of slightly fluctuation, the overall concentrations of As was decreased. Several studies have been deciphered that the effluent of $\mathrm{Mn}$ is attributed to the process of arsenite oxidation by manganese oxides (Lafferty et al., 2010; Oscarson et al., 1983; Tournassat et al., 2002); and it is widely accepted that the oxidation of $\mathrm{As}(\mathrm{III})$ to $\mathrm{As}(\mathrm{V})$ involves in a two-step process, including the release of $\mathrm{Mn}$ (II) and sorption of $\mathrm{Mn}$ (II) on oxidation intermediate (Nesbitt et al., 1998). 
Our results are extremely consistent with those previous studies. As can be drawn from the above picture (Fig.2b) the content of Mn has been increased to an extraordinary magnitude (17-33 folds) compared with the untreated soil. Nevertheless, unfortunately the persistence increasing of $\mathrm{Fe}(\mathrm{II})$ and $\mathrm{Mn}(\mathrm{II})$ in soil porewater under reduced conditions at early growth stages (45-60 days) can inhibited the abiotic oxidation of $\mathrm{As}(\mathrm{III})$ by $\alpha-\mathrm{MnO}_{2}$ nanorods (Ehlert et al., 2014). Another study reported hindered (Fig.2a). Moreover, the impeded As elution has also in turn affected the

\subsection{Enhanced impeded of As accumulation in rice by $\alpha-\mathrm{MnO}_{2}$ nanorods.}

Combined the results which obtained from soil incubation experiments, we can draw a conclusion that the partitioning of As into soil porewater has been rigorous accumulation of As into rice. But the interplay between the addition of $\alpha-\mathrm{MnO}_{2}$ nanorods and As in plant cultivation systems was far more complexity than the pure soil incubation. Pot and field rice cultivation together with soil incubation experiments were therefore combined to clarify the effects of different amounts of $\alpha-\mathrm{MnO}_{2}$ nanorods on the accumulation and translocation of As into rice (Fig.3-7). On the basis of the present study, we believe that there are at least two factors appear to play crucial roles in controlling the As influx into rice plants. 
leads to the subsequently enhanced adsorption of As onto endogenous iron(oxyhydr)

581 oxides; greatly reduced the re-allocation of As into soil porewater, and thus directly

582 cut down the total As transportation into rice parts. As can be seen from the above

583 picture (Fig.3 and Fig.6) The addition of Mn oxides significantly impeded the

584 accumulation of As into subterranean parts (roots $p<0.05$ ); and the associated influx

585 of As into aerial parts (stems, leaves, husk and brown rice) has been also obstructed

586 (Fig.3 and Fig.6; $p<0.05$ ). Correlations analysis (Fig.S4 and Fig.5) between As and

$587 \mathrm{Mn}$ in rice parts can also prove that the transportation of As has been greatly limited.

588 Secondly, apart from those existing fact, As bioavailability could be also

589 mediated through iron and manganese plaque formation on the rice roots and so

590 influence As uptake by rice plants (Liu, 2005; Liu et al., 2005). Therefore, enhanced

591 sequestrate of As by rice roots were probably due to the iron and manganese plaque

592 formation of the rice roots (Fig.3a and Fig.5a). Besides, the addition of manganese

593 oxides can also promote Fe(II) oxidation (Postma and Appelo, 2000); Ehlert et al.

594 (Ehlert et al., 2014) reported that birnessite additions can promote Fe(II) oxidation to

$595 \mathrm{Fe}(\mathrm{III})$, thereby creating newly-formed Fe(III) hydroxides which could serve as

596 efficient sorbents for As(III).

597 Hence, by combination of the obtained facts, we can draw a conclusion that the 598 addition of $\alpha-\mathrm{MnO}_{2}$ nanorods served as a multifunctional role on the As mobilization 599 and transportation in paddy fields. Firstly, the effects on the As fractionation in paddy 600 soil leads to the less dissolution of As in soil porewater. Secondly, As(III) oxidation 
601

602

603

604

605

606

607

608

609

610

611

612

613

614

615

616

617

618

619

620

621

trigged by $\alpha-\mathrm{MnO}_{2}$ nanorods resulted to the adsorption of water soluble $\mathrm{As}(\mathrm{V})$ onto iron oxides. Lastly, the enhanced dissolution of $\mathrm{Mn}$ (II) and Fe(III) can lead to the more iron and manganese plaque formation, which can sequester more As on the surface of rice roots.

\section{Conclusions}

In the present study, soil incubation experiments which combined with pot and field rice cultivation trials were designed to evaluate the effectiveness of exogenous $\alpha-\mathrm{MnO}_{2}$ nanorods on the mobilization and transportation of As in soil-rice systems.

Our results proved that the addition of $\alpha-\mathrm{MnO}_{2}$ nanorods can effectively control the soil-to-solution partitioning of As under anaerobic conditions. The As fractionation can be transformed from effective forms into less effective forms impeded the re-allocation of As into soil porewater, and thus reduced the total amounts of As influx into rice. Besides, the enhanced oxidation of $\mathrm{As}(\mathrm{III})$ into $\mathrm{As}(\mathrm{V})$ by $\alpha-\mathrm{MnO}_{2}$ nanorods greatly increased the adsorption of As onto indigenous iron(hydr) oxides, thus, reduced the soil porewater As. Furthermore, with the simultaneous co-occurrences of the oxidation intermediates of $\mathrm{Mn}(\mathrm{II})$ and $\mathrm{Fe}(\mathrm{III})$, which can probably lead to the enhanced formation of iron and manganese plaque on the surface of rice roots. Combined, the influx of As into aerial parts of rice plants (stems, husk and leaves) was strictly prohibited by rice roots. Nevertheless, it should be noted that the abiotic oxidation of As by $\alpha-\mathrm{MnO}_{2}$ nanorods are greatly impaired by various environmental factors (such as DOM, microbial activities and ligands), thus, further 
work is still needed to verify these results under fields or laboratory scales.

623

624

625

626

627

628

629

630

631

632

633

634

635

636

637

638

639

640

641

642

643

644

645

646

647

648

649

650

651

652

\section{Acknowledgement}

The authors are grateful for financial support from the National Science Foundation of China (41671475/21007014). The author feels extremely thankful to the anonymous reviewers, that work in this paper, for their respected comments and recommendations to increase the quality of this work.

\section{References}

Amstaetter K, Borch T, Kappler A. Influence of humic acid imposed changes of ferrihydrite aggregation on microbial $\mathrm{Fe}(\mathrm{III})$ reduction. Geochimica $\mathrm{Et}$ Cosmochimica Acta 2012; 85: 326-341.

BA M, SE F, B B, DL S. Arsenic(III) oxidation and arsenic(V) adsorption reactions on synthetic birnessite. Environmental Science \& Technology 2002; 36: 976-81.

Balasubramanian N, Kojima T, Srinivasakannan C. Arsenic removal through electrocoagulation: kinetic and statistical modeling. Chemical Engineering Journal 2009; 155: 76-82.

Beiyuan J, Li JS, Dcw T, Wang L, Poon CS, Li XD, et al. Fate of arsenic before and after chemical-enhanced washing of an arsenic-containing soil in Hong Kong. Science of the Total Environment 2017; 599-600: 679-688.

Bontempi E. A new approach for evaluating the sustainability of raw materials substitution based on embodied energy and the $\mathrm{CO} 2$ footprint. Journal of Cleaner Production 2017; 162.

Bruce A. Manning, \$ SEF, Benjamin Bostick A, Suarez§ DL. Arsenic(III) Oxidation and Arsenic(V) Adsorption Reactions on Synthetic Birnessite. Environmental Science \& Technology 2002; 36: 976.

Chen Z, Kim KW, Zhu YG, Mclaren R, Liu F, He JZ. Adsorption (AsIII,V) and oxidation (AsIII) of arsenic by pedogenic Fe-Mn nodules. Geoderma 2006; 136: 566-572.

Cismasu AC, Williams KH, Nico PS. Iron and carbon dynamics during aging and reductive transformation of biogenic ferrihydrite. Environmental Science \& Technology 2015; 50. 
Ehlert K, Mikutta C, Kretzschmar R. Impact of birnessite on arsenic and iron speciation during microbial reduction of arsenic-bearing ferrihydrite. Environmental Science \& Technology 2014; 48: 11320-11329.

Fendorf S, Kocar BD. Biogeochemical processes controlling the fate and transport of arsenic: implications for South and Southeast Asia. Advances in Agronomy 2009; 104: 137-164.

Fu QL, Liu C, Achal V, Wang YJ, Zhou DM. Aromatic Arsenical Additives (AAAs) in the Soil Environment: Detection, Environmental Behaviors, Toxicities, and Remediation. Vol 140, 2016.

Geng A, Wang X, Wu L, Wang F, Chen Y, Yang H, et al. Arsenic accumulation and speciation in rice grown in arsanilic acid-elevated paddy soil. Ecotoxicology \& Environmental Safety 2017; 137: 172.

Gil-Díaz M, Alonso J, Rodríguez-Valdés E, Gallego JR, Lobo MC. Comparing different commercial zero valent iron nanoparticles to immobilize As and $\mathrm{Hg}$ in brownfield soil. Science of the Total Environment 2017; 584-585.

Gil-Díaz M, Diez-Pascual S, González A, Alonso J, Rodríguez-Valdés E, Gallego JR, et al. A nanoremediation strategy for the recovery of an As-polluted soil. Chemosphere 2016; 149: 137-145.

Gilloaiza J, White SA, Root RA, Solísdominguez FA, Hammond CM, Chorover J, et al. Phytostabilization of Mine Tailings Using Compost-Assisted Direct Planting: Translating Greenhouse Results to the Field. Science of the Total Environment 2016; 565: 451.

Goldberg S. Competitive Adsorption of Arsenate and Arsenite on Oxides and Clay Minerals. Soil Science Society of America Journal 2002; 66: 413-421.

Han X, Li YL, Gu JD. Oxidation of As(III) by MnO 2 in the absence and presence of Fe(II) under acidic conditions. Geochimica Et Cosmochimica Acta 2011; 75: 368-379.

Herreweghe SV, Swennen R, Vandecasteele C, Cappuyns V. Solid phase speciation of arsenic by sequential extraction in standard reference materials and industrially contaminated soil samples. Environmental Pollution 2003; 122: 323-342.

Jankong P, Visoottiviseth P, Khokiattiwong S. Enhanced phytoremediation of arsenic contaminated land. Chemosphere 2007; 68: 1906-1912.

Jin HP, Choppala GK, Bolan NS, Chung JW, Chuasavathi T. Biochar reduces the bioavailability and phytotoxicity of heavy metals. Plant \& Soil 2011; 348: 439.

Kumpiene J, Lagerkvist A, Maurice C. Stabilization of $\mathrm{As}, \mathrm{Cr}, \mathrm{Cu}, \mathrm{Pb}$ and $\mathrm{Zn}$ in soil using amendments--a review. Waste Management 2008; 28: 215.

Lafferty BJ, Gindervogel M, Sparks DL. Arsenite Oxidation by a Poorly Crystalline Manganese-Oxide 1. Stirred-Flow Experiments. Environmental Science \& Technology 2010; 44: 8460-6.

Lei M, Tie B, Zeng M, Qing P, Song Z, Williams PN, et al. An arsenic-contaminated field trial to assess the uptake and translocation of arsenic by genotypes of rice. Environ Geochem Health 2013; 35: 379-390.

Lei M, Tie BQ, Song ZG, Liao BH, Lepo JE, Huang YZ. Heavy metal pollution and 
potential health risk assessment of white rice around mine areas in Hunan Province, China. Food Security 2015; 7: 45-54.

Lemonte JJ, Stuckey JW, Sanchez JZ, Tappero RV, Rinklebe J, Sparks DL. Sea level rise induced arsenic release from historically contaminated coastal soils. Environmental Science \& Technology 2017; 51.

Li B, Peng L, Wei D, Lei M, Liu B, Lin Y, et al. Enhanced flocculation and sedimentation of trace cadmium from irrigation water using phosphoric fertilizer. Science of the Total Environment 2017; 601-602: 485.

Li JS, Wang L, Cui JL, Poon CS, Beiyuan J, Dcw T, et al. Effects of low-alkalinity binders on stabilization/solidification of geogenic As-containing soils: Spectroscopic investigation and leaching tests. Science of the Total Environment 2018; 631-632: 1486.

Li M, Wang L, Jia Y, Yang Z. Arsenic speciation in locally grown rice grains from Hunan Province, China: Spatial distribution and potential health risk. Science of the Total Environment 2016; s 557-558: 438-444.

Li R, Zhou Z, Zhang Y, Xie X, Li Y, Shen X. Uptake and Accumulation Characteristics of Arsenic and Iron Plaque in Rice at Different Growth Stages. Communications in Soil Science \& Plant Analysis 2015; 46: 2509-2522.

Liao X, Chen T, Xie H, Xiao X. Effect of application of P fertilizer on efficiency of As removal from As-contaminated soil using phytoremediation: Field study. Acta Scientiae Circumstantiae 2004.

Liao XY, Chen TB, Xie H, Liu YR. Soil As contamination and its risk assessment in areas near the industrial districts of Chenzhou City, Southern China. Environment International 2005; 31: 791-798.

Limmer MA, Wise P, Dykes GE, Seyfferth AL. Silicon Decreases Dimethylarsinic Acid Concentration in Rice Grain and Mitigates Straighthead Disorder. Environmental Science \& Technology 2018; 52: 4809-4816.

Lin L, Gao M, Qiu W, Wang D, Huang Q, Song Z. Reduced arsenic accumulation in indica rice (Oryza sativa L.) cultivar with ferromanganese oxide impregnated biochar composites amendments. Environmental Pollution 2017; 231: 479.

Liu C, Yu HY, Liu C, Li F, Xu X, Wang Q. Arsenic availability in rice from a mining area: is amorphous iron oxide-bound arsenic a source or sink? Environmental Pollution 2015; 199: 95-101.

Liu L, Li W, Song W, Guo M. Remediation techniques for heavy metal-contaminated soils: Principles and applicability. Science of the Total Environment 2018; 633: 206-219.

Liu R, Zhao D. Reducing leachability and bioaccessibility of lead in soils using a new class of stabilized iron phosphate nanoparticles. Water Research 2007; 41: 2491-2502.

Liu WJ. Direct evidence showing the effect of root surface iron plaque on arsenite and arsenate uptake into rice (Oryza sativa) roots. New Phytologist 2005; 165: 91-97.

Liu WJ, Zhu YG, Smith FA. Effects of Iron and Manganese Plaques on Arsenic Uptake by Rice Seedlings ( Oryza sativa L.) Grown in Solution Culture Supplied with Arsenate and Arsenite. Plant \& Soil 2005; 277: 127-138. 
Liu Z, Zhu QQ, Tang LH. Microelements in the main soils of China. Soil Science 1983; 135: 40-46.

Ma JF, Yamaji N, Mitani N, Xu XY, Su YH, Mcgrath SP, et al. Transporters of Arsenite in Rice and Their Role in Arsenic Accumulation in Rice Grain. Proceedings of the National Academy of Sciences of the United States of America 2008; 105: 9931-9935.

Meharg AA. Arsenic in rice--understanding a new disaster for South-East Asia. Trends in Plant Science 2004; 9: 415-417.

Meharg AA, Jardine L. Arsenite transport into paddy rice ( Oryza sativa ) roots. New Phytologist 2003; 157: 39-44.

Nesbitt HW, Canning GW, Bancroft GM. XPS study of reductive dissolution of 7?9-birnessite by $\mathrm{H} 3 \mathrm{AsO} 3$, with constraints on reaction mechanism - Part 1. EXAFS sttudies of the geometry of coprecipitated and adsorbed arsenate. Geochimica Et Cosmochimica Acta 1998: 2097-2110.

Ohtsuka T, Yamaguchi N, Makino T, Sakurai K, Kimura K, Kudo K, et al. Arsenic dissolution from Japanese paddy soil by a dissimilatory arsenate-reducing bacterium Geobacter sp. OR-1. Environmental Science \& Technology 2013; 47: 6263-6271.

Okkenhaug G, Zhu YG, He J, Li X, Luo L, Mulder J. Antimony (Sb) and arsenic (As) in $\mathrm{Sb}$ mining impacted paddy soil from Xikuangshan, China: differences in mechanisms controlling soil sequestration and uptake in rice. Environmental Science \& Technology 2012; 46: 3155.

Oscarson DW, Huang PM, Liaw WK, Hammer UT. Kinetics of Oxidation of Arsenite by Various Manganese Dioxides1. Soil Sci.soc.am.j 1983; 47: 644-648.

Postma D, Appelo CAJ. Reduction of Mn-oxides by ferrous iron in a flow system: column experiment and reactive transport modeling. Geochimica Et Cosmochimica Acta 2000; 64: 1237-1247.

Ren HT, Jia SY, Wu SH, Liu Y, Hua C, Han X. Abiotic oxidation of Mn(II) induced oxidation and mobilization of As(III) in the presence of magnetite and hematite. Journal of Hazardous Materials 2013; s 254-255: 89-97.

Scott MJ, Morgan JJ. Reactions at Oxide Surfaces. 1. Oxidation of As(III) by Synthetic Birnessite. Environmental Science \& Technology 1995; 29: 1898.

Seyfferth AL, Limmer MA, Dykes GE. On the Use of Silicon as an Agronomic Mitigation Strategy to Decrease Arsenic Uptake by Rice. Advances in Agronomy 2018.

Suda A, Makino T. Functional effects of manganese and iron oxides on the dynamics of trace elements in soils with a special focus on arsenic and cadmium: A review. Geoderma 2016; 270: 68-75.

Takahashi Y, Minamikawa R, Hattori KH, Kurishima K, Kihou N, Yuita K. Arsenic Behavior in Paddy Fields during the Cycle of Flooded and Non-flooded Periods. Environmental Science \& Technology 2004; 38: 1038-1044.

Tokunaga S, Hakuta T. Acid washing and stabilization of an artificial arsenic-contaminated soil. Chemosphere 2002; 46: 31-38.

Tournassat C, Charlet L, Bosbach D, Manceau A. Arsenic(III) oxidation by birnessite 
and precipitation of manganese(II) arsenate. Environmental Science \& Technology 2002; 36: 493.

Van HS, Swennen R, Vandecasteele C, Cappuyns V. Solid Phase Speciation Of Arsenic By Sequential Extraction In Standard Reference Materials And Industrially Contaminated Soil Samples. Environmental Pollution 2003; 122: 323-42.

Villen-Guzman M, Gomez-Lahoz C, Garcia-Herruzo F, Vereda-Alonso C, Paz-Garcia JM, Rodriguez-Maroto JM. Specific Energy Requirements in Electrokinetic Remediation. Transport in Porous Media 2017: 1-11.

Wan X, Lei M, Chen T. Cost-benefit calculation of phytoremediation technology for heavy-metal-contaminated soil. Science of the Total Environment 2016; s 563-564: 796-802.

Weber FA, Hofacker AF, Voegelin A, Kretzschmar R. Temperature dependence and coupling of iron and arsenic reduction and release during flooding of a contaminated soil. Environmental Science \& Technology 2010; 44: 116-122.

Wenzel WW, Kirchbaumer N, Prohaska T, Stingeder G, Lombi E, Adriano DC. Arsenic fractionation in soils using an improved sequential extraction procedure. Analytica Chimica Acta 2001; 436: 309-323.

Williams PN, Lei M, Sun G, Huang Q, Lu Y, Deacon C, et al. Occurrence and partitioning of cadmium, arsenic and lead in mine impacted paddy rice: Hunan, China. Environmental Science \& Technology 2009; 43: 637.

$\mathrm{Wu} \mathrm{B}$, Liao XY, Chen TB. Comparison of five methods for fractionation of calcareous soil contaminated with arsenic. Acta Scientiae Circumstantiae 2006; 26: 1467-1473.

$\mathrm{Xu}$ X, Chen C, Wang P, Kretzschmar R, Zhao FJ. Control of arsenic mobilization in paddy soils by manganese and iron oxides. Environmental Pollution 2017; 231: 37-47.

Yamaguchi N, Nakamura T, Dong D, Takahashi Y, Amachi S, Makino T. Arsenic release from flooded paddy soils is influenced by speciation, Eh, $\mathrm{pH}$, and iron dissolution. Chemosphere 2011; 83: 925-932.

Ying SC, Kocar BD, Fendorf S. Oxidation and competitive retention of arsenic between iron- and manganese oxides. Geochimica Et Cosmochimica Acta 2012; 96: 294-303.

Yu P, Zhang X, Wang D, Wang L, Ma Y. Shape-Controlled Synthesis of 3D Hierarchical MnO2 Nanostructures for Electrochemical Supercapacitors. Crystal Growth \& Design 2013; 9: 528-533.

Z Y, W Q, F W, M L, D W, Z S. Effects of manganese oxide-modified biochar composites on arsenic speciation and accumulation in an indica rice (Oryza sativa L.) cultivar. Chemosphere 2017; 168: 341-349.

Zhang RH, Li ZG, Liu XD, Wang BC, Zhou GL, Huang XX, et al. Immobilization and bioavailability of heavy metals in greenhouse soils amended with rice straw-derived biochar. Ecological Engineering 2017; 98: 183-188.

Zhang WX. Nanoscale Iron Particles for Environmental Remediation: An Overview. Journal of Nanoparticle Research 2003; 5: 323-332. 
829 Zhao FJ, Ma Y, Zhu YG, Tang Z, Mcgrath SP. Soil contamination in China: current status and mitigation strategies. Environmental Science \& Technology 2015; 49: 750. arsenic and temporal variation of its concentration in rice. New Phytologist 2011; 189: 200 . 